\title{
An unusual complication during arthrocentesis: N. facialis paralysis, with N. lingualis and N. alveolaris inferior anesthesia
}

\author{
Toghrul Aliyev, Eynar Berdeli, Onur Șahin \\ Department of Oral and Maxillofacial Surgery, Faculty of Dentistry, İzmir Katip Celebi University, İzmir, Turkey
}

\begin{abstract}
This case report aims to review complications that can occur during arthrocentesis and report an unusual complication observed in a 55-year-old man. The patient received arthrocentesis in an attempt to treat painful locking episodes of his right temporomandibular joint (TMJ). One hour after the operation, the patient experienced temporary facial paralysis in the area of the facial nerve and anesthesia of the lingual and alveolar inferior nerves. No persistent complications were detected during the postoperative follow-up. We suspected this complication occurred after anesthetic solution overflowed from a traumatic perforation in the joint capsule to the infratemporal area during the operation. To our knowledge, this complication has not been previously reported in the literature.
\end{abstract}

Keywords: Anesthesia; Arthrocentesis; Complications; Temporomandibular Joint.

\begin{abstract}
This is an Open Access article distributed under the terms of the Creative Commons Attribution Non-Commercial License (http://creativecommons.org/licenses/by-nc/4.0/) which permits unrestricted non-commercial use, distribution, and reproduction in
\end{abstract} any medium, provided the original work is properly cited.

\section{INTRODUCTION}

Temporomandibular disorders (TMDs), depending on the severity, can affect a person's ability to speak, chew, swallow, make facial expressions, and even breathe. There is a complex number of causes for TMD, including bruxism, autoimmune diseases, infections, injuries to the jaw, dental procedures with prolonged opening of the mouth, and various forms of arthritis [1].

Arthrocentesis is a conservative surgical approach used to treat internal irregularities in the temporomandibular joint (TMJ). It is especially successful for reducing pain in patients who suffer from trismus or locking of the TMJ $[2,3]$. The reported complications after arthrocentesis are minimal (between $1.8 \%$ and $10.3 \%$ ), making it a routine oral and maxillofacial surgical procedure [4-6].

Reported complications in the literature include otologic injuries (tympanic membrane perforation, hemotympanum, external auditory canal embolus, external auditory canal stenosis, hearing loss, aural fullness), pre-auricular hematoma, aneurysm of the superficial temporal artery, arteriovenous fistula, transarticular perforation, intracranial perforation, extradural hematoma, parapharyngeal swelling, intraarticular issues (hemarthrosis, arthritis, bacterial infection) and intraarticular needle fragmentation $[7,8]$.

This case report aimed to present an unusual complication of arthrocentesis that has never been reported and describe methods for preventing such a complication.

Received: January 22, 2019 • Revised: March 12, 2019 • Accepted: March 19, 2019

Corresponding Author: Onur Şahin, Department of Oral and Maxillofacial Surgery, Faculty of Dentistry, İzmir Katip Çelebi University, Aydınlıkevler Mah. 6782 Sok. No: 4835640 Çiğli, İzmi, Türkiye

Fax: +90 (232) 3252535 E-mail: onursahin43@hotmail.com

Copyright(c) 2019 Journal of Dental Anesthesia and Pain Medicine 


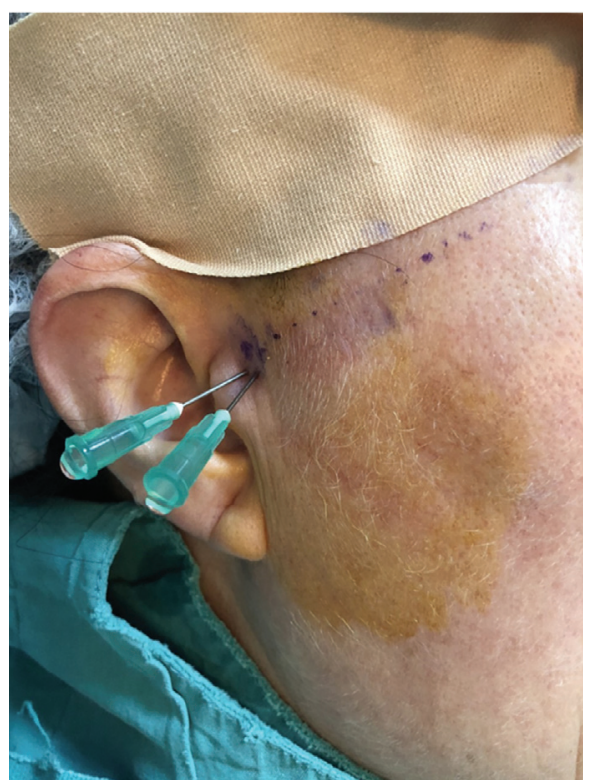

Fig. 1. Entry points in double-needle technique on right temporomandibular joint.

\section{CASE}

A 55-year-old man was referred to our department with severe bruxism that caused painful jaw locking and trismus in the right TMJ. He had undergone arthrocentesis twice at another center. The patient had a medical history of hypertension and was taking amlodipine. There was no history of smoking or alcohol use.

An arthrocentesis with an intraarticular sodium hyaluronate injection was planned to alleviate the patient's symptoms under local anesthesia. For two weeks before the operation, the patient used a non-steroidal anti-inflammatory and muscle relaxants. To reduce the strain of muscle tonus and bruxism, an acrylic occlusal splint was designed for the patient, and he was asked to massage his masticatory muscles with a hot compress and to perform the abeslang test.

At the start of the arthrocentesis procedure, to reduce pain and pressure, the patient was superficially anesthetized and administered $2 \mathrm{ml}$ of $4 \%$ articaine hydrochloride with 1:200,000 epinephrine intraarticularly. The arthrocentesis procedure was performed using two needles (Fig. 1), as described by Nitzan et al. [9]. A 21-G cannula was inserted into the upper joint cavity and distension of joint capsule was accomplished by injecting $2 \mathrm{ml}$ of lactated ringer solution. Placement of a second 21-G cannula proved difficult due to the narrowness of the upper joint cavity and was attempted multiple times. Later, the cannulas were transfused, and arthrocentesis was started using a $50 \mathrm{ml}$ syringe to inject $100 \mathrm{ml}$ of lactated ringer solution. The patient felt some pain during the operation, so another $0.5 \mathrm{ml}$ of articaine hydrochloride was given and arthrocentesis continued with $100 \mathrm{ml}$ of lactated ringer solution. Due to ongoing pain and discomfort, the wash out process was terminated. The patient experienced dizziness and nausea for some time after the operation. The patient was observed for nearly an hour, during which his blood pressure and blood sugar were measured three times, each with normal values. After complaints of dizziness and nausea started to resolve, a paralysis was detected on patient's right $\mathrm{N}$. facialis and anesthesia of $\mathrm{N}$. alveolaris inferior and $\mathrm{N}$. lingualis. The patient was kept under observation in the clinic and discharged two hours later. The next day, no complications were detected upon follow-up examination.

\section{DISCUSSION}

Wash out of inflammatory and bonding mediators to clean any adhesions on the joint disc and fossa is a simple and effective surgical method first suggested by Nitzan et al. [9] in 1991. Although intraarticular irrigation is a reliable method, complications can be observed due to joint anatomy, arthrocentesis technique and surgeon experience. Many complications have been reported after arthrocentesis under local anesthesia. These complications are typically secondary to two factors: mechanical damage caused by the cannula or local anesthesia which can lead to allergic reactions, facial paralysis, and vertigo, as well as dizziness and hearing difficulty when the middle ear is affected during the arthrocentesis procedure [5].

Carrol et al. [6] reported that a 59-year-old woman who 
remained drowsy and developed left hemiparesis following right TMJ arthrocentesis and lavage for TMJ dysfunction. After the operation, computed tomography (CT) revealed that an extradural hematoma occurred where the cannula passed the TMJ and pricked the intracranial portion of the middle meningeal artery. With a brain surgeon's intervention, the hematoma was removed, and no perforation of the dura nor damage to bone of the central cranial fossa was reported.

Vaira et al. [4] reported that a 48-year-old female suffered from an independently regressing short term vertigo attack after local anesthesia (mepivacaine $2 \%$ and 1:200,000 epinephrine) was given before arthrocentesis. She complained of severe objective vertigo due to extravasated anesthetic solution reaching to the semicircular canals near the inner ear as a result of transarticular penetration. She experienced nausea, vomiting and grade 3 nystagmus. Once the anesthetic solution dissipated, the symptoms resolved and the patient never suffered from ongoing hearing loss or vertigo.

In 2018, Vaira et al. [7] published a study that evaluated the complications of 433 arthrocentesis procedures performed in 315 patients. In their study, it was reported that temporary swelling of the periarticular tissues $(95.1 \%)$ or the external auditory canal (23.5\%), ipsilateral temporary open bite $(68.8 \%)$, frontalis and orbicularis oculis paresis $(65.1 \%)$, preauricular hematoma $(0.4 \%)$ and case of vertigo $(0.2 \%)$ were the complications detected. Once the local anesthesia wears off, a full regression of symptoms occur.

Gonzalez et al. [10] showed that otologic complications may occur after arthrocentesis due to the close proximity of the TMJ to the external auditory canal, tympanic membrane and middle ear. They reported problems such as bleeding, needle fragmentation, external auditory canal laceration or blood clot, facial paralysis, and lesions of $\mathrm{N}$. auriculotemporalis or $\mathrm{N}$. alveolaris inferior.

The use of local anesthesia with arthrocentesis can cause swelling of neighboring tissues or temporary facial paralysis $[4,11]$.

In the research conducted by Yavuz and Keskinruzgar
[12], 18 complications were observed in 102 arthrocentesis procedures, including temporary swelling $(0.98 \%)$, hemorrhage $(0.98 \%)$, facial paralysis $(1.96 \%)$, lingual anesthesia $(0.98 \%)$, inferior nerve anesthesia $(0.98 \%)$, tachycardia $(0.98 \%)$, syncope $(2.94 \%)$, dizziness $(4.9 \%)$, severe pain $(0.98 \%)$, and trismus $(1.96 \%)$.

In this case report, it is likely that complications observed in the three nerves during arthrocentesis are secondary to the anesthetic solution, which was pushed to the infratemporal area as a result of a perforation or mechanical damage caused by the cannula. To prevent this condition, TMJ and regional anatomy should be well researched to keep extravasation to a minimum and avoid reaching the infratemporal fossa with the arthrocentesis cannula. Excessive use of epinephrine should be avoided and the operation should be performed by an experienced surgeon.

In conclusion, although arthrocentesis is a reliable method, complications may occur during and after the procedure due to the operation site's proximity to important anatomical structures. To avoid these complications, obtaining detailed patient history and imaging using magnetic resonance imaging, CT, or cone-beam CT are essential before surgery. The anatomical structure of the patient, experience of the clinician, and arthrocentesis technique are important in this regard. Paralysis of $\mathrm{N}$. facialis and anesthesia of N. lingualis and N. alveolaris inferior may be observed during arthrocentesis depending on the anesthesia technique and complications. It is recommended that extravasation be kept to a minimum level to prevent this complication.

\section{AUHOR ORGIDS}

Toghrul Aliyev: https://orcid.org/0000-0002-6312-476X

Eynar Berdeli: https://orcid.org/0000-0001-8729-9479

Onur Şahin: https://orcid.org/0000-0001-7816-1443

CONFLICT OF INTEREST: All authors declared no conflict of interest.

FUNDING: No source of funding was used in this study. 


\section{REFERENCES}

1. Ohrbach R, Fillingim RB, Mulkey F, Gonzalez Y, Gordon $\mathrm{S}$, Gremillion $\mathrm{H}$, et al. Clinical findings and pain symptoms as potential risk factors for chronic TMD: descriptive data and empirically identified domains from the OPPERA casecontrol study. J Pain 2011; 12: T27-T45.

2. Tvrdy P, Heinz P, Pink R. Arthrocentesis of the temporomandibular joint: a review. Biomed Pap Med Fac Univ Palacky Olomouc Czech Repub 2015; 159: 31-4.

3. Al-Moraissi EA. Arthroscopy versus arthrocentesis in the management of internal derangement of the temporomandibular joint: a systematic review and meta-analysis. Int J Oral Maxillofac Surg 2015; 44: 104-12.

4. Vaira LA, Soma D, Meloni SM, Dellaversana Orabona G, Piombino P, De Riu G. Vertiginous crisis following temporomandibular joint arthrocentesis: a case report. Oral Maxillofac Surg 2017; 21: 79-81.

5. Keskinruzgar A, Cankal DA, Koparal M, Simsek A, Karadag AS. Investigation of the effects of temporomandibular joint arthrocentesis on blood volume of the retinal structures. J Dent Anesth Pain Med 2019; 19: 37-44.

6. Carroll TA, Smith K, Jakubowski J. Extradural haematoma following temporomandibular joint arthrocentesis and lavage. Br J Neurosurg 2000; 14: 152-4.
7. Vaira LA, Raho MT, Soma D, Salzano G, Dellaversana Orabona G, Piombino P, et al. Complications and postoperative sequelae of temporomandibular joint arthrocentesis. Cranio 2018; 36: 264-7.

8. McCain JP, Sanders B, Koslin MG, Quinn JH, Peters PB, Indresano AT. Temporomandibular joint arthroscopy: a 6-year multicenter retrospective study of 4,831 joints. J Oral Maxillofac Surg 1992; 50: 926-30.

9. Nitzan DW, Dolwick MF, Martinez GA. Temporomandibular joint arthrocentesis: a simplified treatment for severe, limited mouth opening. J Oral Maxillofac Surg 1991; 49: 1168-70.

10. Gonzàlez-Garcìa R, Rodrìguez-Campo FJ, EscorialHernàndez V, Muoz-Guerra MF, Sastre-Perez J, Naval Gias L, et al. Complications of temporomandibular joint arthroscopy: a retrospective analytic study of 670 arthroscopic procedures. J Oral Maxillofac Surg 2006; 64: 158791.

11. Nitzan DW, Dolwick MF. An alternative explanation for the genesis of closed lock symptoms in the internal derangement process. J Oral Maxillofac Surg 1991; 49: 810-5.

12. Yavuz GY, Keskinruzgar A. Evaluation of complications of arthrocentesis in the management of the temporomandibular joint disorders. Galore Int J Health Sci Res 2018; 3: $50-3$ 